\title{
Juventudes e as múltiplas maneiras de ser jovem na atualidade
}

\author{
Youths and the multiple ways of being young today
}

http://dx.doi.org/10.5007/2178-4582.2014v48n2p247

\author{
Mara Regina Zluhan e Tânia Regina Raitz \\ Universidade do Vale do Itajaí, Itajai/SC, Brasi
}

\begin{abstract}
Os estudos realizados com os jovens nas últimas décadas têm demonstrado que há uma multiplicidade de conceitos acerca da juventude. Neste sentido, o objetivo deste artigo de revisão é identificar a diversidade de juventudes presentes nas escolas de Ensino médio, analisando como elas se constituem em alunos e como a escola está organizada para atender a essa faixa etária. Com o presente estudo, oferecemos como considerações que é fundamental que os jovens reconheçam o valor da escola para a sua formação, integrando-se à sua organização e às suas práticas, rompendo com a distância entre os objetivos individuais, escolares e de aprendizagem. Um caminho para superar esse dualismo são os estudos e programas de formação sobre a juventude, que podem contribuir para a criação de uma escola significativa, auxiliando o jovem na transição para a vida acadêmica ou para o mundo do trabalho.
\end{abstract}

Palavras-chave: Jovens do Ensino médio - Sujeitos Educacionais - Transição
Studies on young people in recent decades have shown that there is a multiplicity of concepts about youth. In this sense, the objective of this review paper is to identify the diversity of youths present at the high schools, analyzing how they constitute into students and how the school is organized to meet this age group. With this study, we consider that is essential that young people recognize the value of school for their education, integrating themselves into this organization and its practices, breaking the distance between the individual, schools and learning goals. A way to overcome such dualism are those studies and training programs on youth, which may contribute to the creation of a significant school by helping young people in the transition to academic life or to the world of work.

Keywords: Young high school students - Educational subjects - Transition.

\section{Introdução}

O presente artigo de revisão pretende identificar os principais atores do Ensino médio, ou seja, os jovens. Os estudos sobre a vida juvenil têm ocupado gradativamente maior espaço na área educacional, tendo em vista que esta fase não é composta somente por elementos de transitoriedade. Ao contrário, existem inúmeros aspectos e características que necessitam ser estudados e pesquisados a fim de conhecer os conflitos, anseios e projetos de vida dos jovens, relacionando-os com as múltiplas maneiras de existir, in- 
dividual e coletivamente, bem como com os significados que eles atribuem à escola.

Quando se fala em Ensino médio, normalmente se faz referência imediata à juventude. Com frequência, essa faixa etária é caracterizada como um período de conflitos, divergências e desordens, por meio de vários estereótipos e pela homegeneização da cultura juvenil. No entanto, há que se considerar as diversidades e complexidades que permeiam a constituição desses sujeitos e que estão diretamente relacionadas aos fatores históricos, culturais e sociais, definindo as especificidades de cada contexto. Neste sentido, o objetivo do presente artigo é identificar a diversidade de juventudes presentes no meio educacional, analisando como eles se constituem em alunos e como a escola está organizada para atender a essa faixa etária.

Diante da complexidade de mudanças que a escola foi chamada a executar nas últimas décadas em termos de acesso, diferentes modalidades de ensino, tempo de permanência, avaliações externas, entre outras inúmeras questões, há que se pensar que não há mais espaço para uma escola apartada do contexto social e cultural que a compõe. Requer-se que a escola mantenha um contínuo processo de reflexão e estudos sobre juventude e processos de escolarização, já que vêm progressivamente perdendo relevância na constituição cognitiva, social e ética dos jovens, que deslocam, para outros espaços como o consumo, a mídia e as tecnologias, o seu centro de interesse e atenção.

$\mathrm{O}$ artigo está dividido em duas partes: a primeira irá discutir as múltiplas maneiras de ser jovem, as diversidades que compõem esse momento de transição, bem como as diferentes maneiras de se conceituar a juventude. Já a segunda parte do texto descreve o jovem como sujeito educacional, analisando os sentidos culturais que são elaborados nos grupos juvenis que integram o Ensino médio e os significados que eles atribuem à escola.

\section{Juventude, multiplicidade e diversidades}

Por longas décadas, as pesquisas sobre juventude priorizaram o enfoque dos elementos de transitoriedade, dos desajustes sociais, do viés político e do trabalho, dando pouca visibilidade aos processos educacionais e às formas como os jovens se percebem como atores da sua trajetória, evitando ouvi-los em relação às suas expectativas, significados e experiências educacionais. Desde os anos de 1990, quando o tema juventude começou a conquistar maior espaço na agenda pública e nas pesquisas e estudos das áreas da Pedagogia, Psicologia, Sociologia e Antropologia, ampliou-se o interesse de estudo desta temática. Sposito afirma: 
O tema juventude alcançou maior visibilidade nos últimos quinze anos no Brasil como produto da intersecção de vários domínios da vida social e da ação de diferentes atores. Os jovens entram na pauta das políticas públicas como parte da questão social e do crescimento da violência no país. Iniciativas também observadas neste período, em um primeiro momento nas prefeituras e posteriormente em âmbito federal, tentam trazer para a arena pública novas visibilidades em torno dos segmentos juvenis, considerados como atores capazes de ação e de interlocução política. Há, assim, uma confluência de demandas e de representações no campo político que se torna uma arena bastante diversificada de iniciativas e de concepções em torno da questão juvenil no país. (SPOSITO, 2010, p.17)

Existem formas distintas de caracterizar a juventude, considerando-se que as categorias sociais foram divididas e subdivididas de diversas formas ao longo da história: infância, adolescência, juventude, jovem-adulto, adulto, maturidade, idoso, velho, terceira idade, quarta idade, de acordo com a cultura de cada época, os reconhecimentos legais, a prática cotidiana, entre outros. Groppo (2000) refere-se à fase de ingresso na maturidade por meio de três divisões: a medicina elaborou o conceito de puberdade, referindo-se às modificações corporais; a psicologia, a psicanálise e a pedagogia criaram o conceito de adolescência, referindo-se às mudanças na personalidade, na mente ou no comportamento; já a sociologia aborda as funções sociais na transição da infância para o mundo adulto.

Melucci e Fabbrini (1992, apud DAYRELL, 2003) defendem que as mudanças físicas e psicológicas ocorridas na juventude são muito variadas e diretamente influenciadas pelas condições sociais, culturais, de gênero e de regiões geográficas. Existem diversos sinais corporais e psicológicos que acenam para o início da juventude, entre eles a procriação, o desejo de menos proteção da família, quando o jovem busca a independência e assume novas responsabilidades. No entanto, Dayrell faz uma importante análise dos fenômenos evolutivos que cercam a juventude,

[...] uma sequência temporal não implica necessariamente uma evolução linear, na qual ocorra uma complexidade crescente, com a substituição das fases primitivas pelas fases mais maduras, de tal forma a cancelar as experiências precedentes. [...] Assim a adolescência não pode ser entendida como um tempo que termina, como a fase da crise ou de trânsito entre a infância e a vida adulta, entendida como a última meta da maturidade. Mas representa o momento do início da juventude, um momento cujo núcleo central é constituído de mudanças do corpo, dos afetos, das referências sociais e relacionais. Um momento no qual se vive de forma mais intensa um conjunto de transformações que vão estar presentes, de algum modo, ao longo da vida. (MELUCCI; FABBRINI, 1992, apud DAYRELL, 2003, p.42) 
Diante dos diferentes aspectos que configuram a juventude, a sua compreensão não se dá unicamente pela ótica biológica, psicológica ou pedagógica, buscando-se na interdisciplinaridade os recursos necessários para a compreensão da diversidade cultural e também das desigualdades sociais e econômicas que marcam a sua condição, evitando-se, assim, os reducionismos ou as formas fragmentadas de entender esse processo de transição. Muitos estudos representam a juventude somente como um processo de mudanças ou um momento de transitoriedade, no qual os jovens se mostram incapazes de ampliar a definição de características, práticas sociais e outros elementos constitutivos que são essenciais e vitais para a compreensão da vida juvenil. Desta forma, o termo demanda complexidade quando se trata de definir juventude na atualidade, tendo em vista que se utilizam critérios, tais como, o contexto sociocultural, o status social, econômico e jurídico, entre outros, entendendo-se que se refere a um conceito aberto, permanentemente construído no contexto do processo histórico-cultural (MELO; BORGES, 2007).

As versões adultocêntricas atribuídas à juventude costumam figurar em muitos discursos e práticas educativas, definindo as vivências e particularidades dessa faixa etária pelas referências dos adultos, discriminando as formas particulares de ser e estar jovem. No entanto, as experiências de cada geração são distintas e precisam ser analisadas em suas especificidades. A escola, por muitos séculos foi moldada de acordo com a sociabilidade adulta, porém, os critérios estabelecidos não estão dando conta de responder às novas características da sociabilidade juvenil, exigindo da mesma compreensão e estudo. Dayrell afirma:

É comum também entre os professores o estereótipo das gerações atuais como sendo desinteressadas pelo contexto social, individualistas e alienadas, numa tendência a compará-las com às gerações anteriores, mitificadas como gerações mais comprometidas e generosas (DAYRELL, 2009, p.16).

A partir dos conceitos de juventude sob a ótica da adultização, há uma tendência do senso comum a relacionar a juventude com desvios, conflitos e violência, tratando-a como um problema e não como um campo possível para a problematização. É necessário configurar o lugar social desses jovens, porque a sua condição irá definir seus limites e possibilidades. As violências juvenis, delinquências e brigas estão associadas, na maioria das vezes, à violência estrutural e generalizada que permeia a sociedade brasileira (DAYRELL, 2009). Centenas de jovens são vítimas diárias da violência no Brasil e abre-se uma discussão a nível nacional para buscar soluções para esse quadro que é cada vez mais preocupante e ameaçador. A escola por sua vez, assume um papel 
fundamental de prevenção, já que as práticas de convivência são importantes instrumentos para superar o desrespeito, a falta de tolerância quanto às diversidades e o preconceito. Ainda em relação à violência juvenil, Frigotto acrescenta:

Há um número significativo de jovens das grandes capitais, violentados em seu meio e em suas condições de vida, que se enquadram em uma situação de risco permanente e que são alvo das mais diversas formas de violência, sendo a mais cínica a do Estado, sob o pretexto do 'choque de ordem'. Trata-se de grupos de jovens que foram tão desumanizados e socialmente violentados que se tornaram presas fáceis do 'mercado da prostituição infanto-juvenil' ou de gangues, que nada têm a perder ou constituem um 'exército de soldados do tráfico' (FRIGOTTO, 2009, p. 25).

Os estudos que tratam da juventude, por longas décadas, priorizaram os temas relacionados aos problemas sociais, porém, atualmente, existem diversos outros indicadores que enfocam questões da vida juvenil, entre eles os que apontam para a definição do final da juventude. A entrada para a vida adulta normalmente é definida por meio da conclusão dos estudos, o ingresso no mercado de trabalho, a saída da casa dos pais e a constituição de uma nova família. Diante das transformações que estamos vivendo na atualidade, esses eventos não ocorrem mais de forma linear e, portanto, provocam incertezas e a assunção de novos papéis que afetam os projetos e planos de futuro. Chamboredon (1985) considera a multiplicidade e a desconexão das diferentes etapas de entrada da vida adulta:

Em decorrência tanto da descristalização, significando dissociação no exercício de algumas funções adultas, e a latência, que separa a posse de alguns atributos do seu imediato exercício, seriam elementos importantes para o estudo dos jovens nos dias atuais. O primeiro caso - a descristalização — oferece como exemplo o exercício das atividades adultas da sexualidade já na puberdade, dissociado das funções reprodutivas e familiares. $\mathrm{O}$ segundo caso - a latência seria ilustrado pela situação de posse de habilitação profissional oferecida pelo sistema escolar sem o imediato ingresso no mercado de trabalho, situação típica de países como a França (apud SPOSITO, 1997, p. 21).

Discute-se hoje o conceito da prolongação da juventude. Diversos fatores contribuem para o retardamento do ingresso na vida adulta, entre eles, a dificuldade de ingresso no mercado de trabalho, os altos índices de desemprego, a precarização do trabalho e a dificuldade de inserção na área de formação. Diante desses obstáculos, o jovem busca maior especialização, ampliando, 
desta forma, o tempo de permanência no mundo escolar/acadêmico, através do ingresso em programas de pós-graduação, cursos técnicos, estágios complementares, a fim de qualificar seu perfil profissional. É necessário salientar que esse fenômeno se estende a uma reduzida parcela da população, que possui condições financeiras de manter seus filhos somente estudando, já que,74\% dos jovens brasileiros estão trabalhando ou procurando emprego, enquanto $37 \%$ estão somente estudando (BRASIL, 2013).

Diante desta situação, muitos jovens optam por permanecer na casa dos seus pais, por conta das comodidades que lá encontram. Essa opção pode ser justificada pela modificação das relações entre pais e filhos configuradas nas últimas décadas. Se antes existiam rígidas normas de comportamento e exigências pautadas pelo mundo adulto, atualmente a juventude se transformou em um estilo de vida, caracterizando-se não pela faixa etária, mas por uma opção de eterna juventude. A flexibilização e a abreviação dos laços afetivos, a diluição de fronteiras e limites, a fragilidade dos vínculos trabalhistas, os deslocamentos constantes, entre outros, são fatores que modificam as relações familiares, sociais e de trabalho e instituem uma nova constituição do sujeito. Neste sentido, La Taille, Silva e Justo salientam:

\begin{abstract}
A vida, antes fortemente situada num determinado lugar, como a cidade, a casa, a família, a empresa, o trabalho, a profissão, os amores, as paixões, os adversários e assim por diante, ou seja, aquela vida estável, mesmo que fosse na pobreza, porém, assentada em vínculos sólidos, duradouros e produtores de proximidade entre as pessoas, estaria cedendo lugar para um modo de vida marcado pelo abrandamento, pela fragilização, e pela provisoriedade de vinculações do sujeito a territórios sociais e afetivos (2005, p.30).
\end{abstract}

Por outro lado, há uma parcela da juventude que desde muito cedo assume o status de adulto. São aqueles que ingressam precocemente no mundo do trabalho e são chamados a desempenhar tarefas e assumir comportamentos e responsabilidades (produtiva, conjugal, doméstica, parental) do mundo adulto. Nestes casos, o salário é fundamental para contribuir no orçamento doméstico. Geralmente a elevada carga horária os impede de dedicar um tempo mínimo às exigências escolares, refletindo negativamente no seu desempenho. Em muitos casos, a própria família não destina o valor necessário à educação, preferindo que o jovem trabalhe e ajude no pagamento das despesas familiares, não motivando a sua permanência na escola. De acordo com a Agenda Juventude Brasil (BRASIL, 2013) o trabalho fez ou faz parte da experiência de vida de 4 em cada 5 jovens brasileiros, o que nos leva a afirmar que a juventude brasileira é uma juventude trabalhadora. Por outro lado, 
a pesquisa demonstra que houve um acréscimo na escolaridade, já que 59\% estão no Ensino médio e 39\% já concluíram esse nível de ensino. Frigotto ressalta:

Todos esses grupos têm suas especificidades mas, do ponto de vista psicossocial e cultural, tendem a sofrer um processo de adultização precoce. A inserção no mercado formal ou 'informal' de trabalho é precária em termos de condições e níveis de remuneração. Uma situação, portanto, muito diversa da dos jovens de 'classe média' ou filhos dos donos de produção, que estendem a infância e a juventude (2009, p. 25).

Diante da condição de provisoriedade e das incertezas, o jovem convive cotidianamente com a ameaça de ficar para trás, de ser excluído do jogo, de ser incapaz de atender as novas exigências e demandas. Essa ansiedade constante, em muitos casos, leva a uma perda de perspectiva de futuro, invadindo o presente e gerando uma certa imobilidade diante dos fatos. Segundo Bauman:

\begin{abstract}
[...] nada nesse mundo se destina a durar, que dirá para sempre. Objetos hoje recomendados como úteis e indispensáveis tendem a 'virar coisa do passado' muito antes de terem tempo de se estabelecer e se transformar em necessidade ou hábito. Nada é visto como estando aqui para sempre, nada parece insubstituível. Tudo nasce com a marca da morte iminente e emerge da linha de produção com o 'prazo de validade' impresso ou presumido [...] (2013, p.22).
\end{abstract}

Bauman (Ibid.) continua dizendo que as agendas de políticas sociais e culturais destinadas para a juventude são um tanto ineficazes e insuficientes e que essa categoria somente não é dispensável pelo potencial de consumo que representa. Existe uma série de evidências que demonstram a preocupação de adestrar os jovens para o consumo, encontrando no excesso e na extravagância dois importantes impulsos para manter a economia consumista. Evidencia-se uma cultura do desengajamento, da descontinuidade e do esquecimento, que promove o culto da novidade e do suprimento excessivo de todas as coisas, tanto dos objetos de desejo, quanto do conhecimento. Para manter esse mercado de consumo, Baumann destaca que é necessário:

[...] evitar que qualquer coisa praticada no momento se transforme em hábito; não ficar preso pelo legado do próprio passado; usar a identidade atual como uma camisa que pode prontamente ser substituída quando sai de moda; desdenhar das velhas lições e das antigas habilidades sem inibição ou remorso [...] (2013, p.36). 
Outro fator importante na configuração da cultura juvenil refere-se ao impacto das tecnologias, já que a internet, as redes sociais, os telefones celulares, a TV, entre outros, ocupam um lugar central no cotidiano de seus usuários. O mundo virtual desencadeou uma série de modificações na vida do jovem, no que tange às suas relações, no contato com as informações, na forma de aprender, de produzir significados e conhecimentos. Diante dessa nova configuração juvenil, estamos distante de respostas definitivas sobre o impacto das tecnologias virtuais no desenvolvimento humano, o que requer a tarefa de interpretação do que se sucede, de modo a permitir uma avaliação desse processo.

A geração Net (GARBIN, 2009) transita com propriedade entre chats, e-mails, sites, blogs, webzines, ao mesmo tempo que vê TV, troca de canal, comenta o que viu, ouve música, enfim, utiliza simultaneamente diversos recursos tecnológicos. Esses espaços se configuram como importantes recursos no sentimento de pertencimento dos jovens, atribuindo significados aos seus fazeres e transformando-se em um importante meio de expressividade e maneiras de ser e estar no mundo.

Assim, pode-se inferir que existe uma multiplicidade de elementos que compõem as juventudes, esses construídos historicamente e que se distinguem de acordo com o tempo e espaços sociais, constituindo-se em uma representação sociocultural. Dessa forma, faz-se necessário entender as diversas características, significados e transformações para prover-se de recursos que permitam o entendimento da cultura juvenil.

\section{O jovem como sujeito educacional}

A educação básica brasileira conquistou inúmeros avanços nas últimas décadas no que se refere à universalização do ensino e ao crescente avanço dos índices de aprendizagem. Porém, esses números ainda são tímidos, exigindo que as políticas públicas busquem meios para avançar na qualidade, principalmente no Ensino médio, que ainda se convive com grandes dificuldades e obstáculos, demonstrados pelos números alarmantes de evasão e reprovação. Conforme dados do Censo Escolar da Educação Básica (BRASIL, 2012), o Brasil possui 10.580.060 jovens na idade entre 15 e 17 anos; dos quais somente 8.400 .689 estão matriculados no ensino médio. Deste número de matriculados, tem-se alguns que não concluirão o curso, seja pela repetência e ou pela evasão escolar.

Este elevado número de adolescentes e jovens fora da escola deve ser analisado por vieses distintos. Percebe-se que não há um único elemento cata- 
lisador do alto índice de evasão/abandono escolar no ensino médio, tampouco se pode afirmar que a escola seja a única responsável por este quadro. Soma-se a ela uma série de questões, tais como o contexto social, familiar, as políticas de governo e o próprio aluno, que deixa de acreditar que a escolaridade possa garantir-lhe um futuro melhor. É comum ouvirmos indagações como: para que estudar? Para que serve isso? O que vou ganhar com um diploma? As respostas padrão costumam lançar para o futuro a relevância do conhecimento e o fato de eles não perceberem a importância imediata da aprendizagem em suas vidas, dificulta a sua aderência ao cotidiano escolar. Souza nos faz compreender que:

[...] a escola vivencia o drama da obrigação, e com isso, raramente incentiva a liberdade de criar e criar-se. Com seu pensamento lógico, enquadra a apreensão do mundo em classificações e seriações. [...] os conteúdos ensinados sofrem antes uma profunda assepsia: são higienizados, despolitizados, dessexualizados, deshistoricisados, desintegrados, desvivenciados, descomunitários (2006, p.09).

O ensino médio vive uma crônica crise de identidade no que se refere à preparação dos jovens para o mercado de trabalho ou para o ingresso no ensino superior. A adoção de um sistema único, que oferece a mesma escola para todos difere dos modelos propostos em outros países, que adotam vertentes acadêmicas e profissionalizantes, aceitando e trabalhando com a heterogeneidade dos alunos. Kuenzer (2000) critica o modelo brasileiro de ensino médio, afirmando que, apesar da implantação da sua obrigatoriedade, constituindose em um importante passo rumo à universalização, a adoção de um modelo único de formação geral reveste-se de um caráter excludente, impelindo os jovens que precisam trabalhar ao abandono ou à busca por cursos profissionais. Diante da fragilização do ensino médio, Oliveira (2012), destaca que para entender essa etapa de ensino e sua atual crise estrutural e pedagógica torna-se indissociável:

[...] uma leitura das políticas públicas vigentes, as quais [...] reúnem diariamente, no interior das salas de aula brasileiras, jovens cujos destinos sociais já se encontram fixados, pré-determinados pela precarização da vida pessoal de seus professores mal remunerados e pelo abandono estrutural a que se veem confinados em suas escolas; no entanto, esses mesmos sujeitos comumente são proclamados publicamente como participantes de um processo nomeado de universalização do ensino médio[...] (OLIVEIRA, 2012, p.49-50) 
Conforme dados do Censo Escolar da Educação Básica (BRASIL, 2012), o Brasil ainda convive com altos índices de repetência e evasão escolar.

\begin{abstract}
[...] a evasão escolar entre jovens é alarmante. Dos 3,6 milhões de jovens que se matriculam no Ensino médio, apenas 1,8milhão concluem esse grau. A taxa de evasão é de $13,3 \%$ no Ensino médio contra $6,7 \%$ de $5^{\text {a }}$ a $8^{\mathrm{a}}$ série e $3,2 \%$ de $1^{\mathrm{a}}$ a $4^{\mathrm{a}}$ série. $\mathrm{O}$ Brasil tem, atualmente, 8,3 milhões de alunos no Ensino médio, matriculados em 24 mil escolas - sendo 17 mil públicas - e metade dos alunos, conforme o Ministério da Educação, não finalizam seus estudos (BRASIL, 2012).
\end{abstract}

O que está acontecendo com esse modelo escolar que não consegue atrair e manter o segmento juvenil? A escola foi historicamente pensada para oferecer às crianças e jovens o conhecimento necessário para a concretização dos seus projetos pessoais sociais e para sua inserção cidadã no meio que os cerca. No entanto, muitos deles declaram a sua insatisfação com a escola, afirmando que esta não possibilita espaços de diálogos, de participação, não proporciona aulas atraentes, com recursos inovadores, não promove atividades culturais e recreativas que possam ampliar a sociabilidade e a interação entre os grupos. Ou seja, além dos vários problemas da vida cotidiana com os quais a grande maioria dos jovens de classes desfavorecidas precisa conviver - tais como a busca por emprego, baixos salários, falta de moradia, gravidez na adolescência, entre outros - ainda precisam lidar com a falta de significação do processo educativo.

É desconcertante imaginar que muitos jovens passam doze anos na escola e saem dela sem saber resolver problemas básicos do seu cotidiano, sem conseguir estabelecer relação dos conteúdos estudados com suas experiências de vida, tampouco proceder a uma leitura de mundo. Esse quadro configura uma crise nos modelos educacionais vigentes, cujas finalidades são questionadas frente à necessidade de experimentações, das novidades, do cultivo de novas sensações e desafios. Os valores juvenis estão distantes da disciplina, do esforço pessoal, da transmissão de conhecimentos significados pela escola, fazendo surgir um desencontro de expectativas e, por consequência, tensões e conflitos no meio escolar. Andrade (2000, p. 88) ressalta a importância de estudos que apontem "a busca de novas alternativas educacionais relacionadas ao campo da educação, da cultura e do trabalho, que atentem às especificidades desses grupos $[\ldots]$ "..

Para que novas perspectivas educacionais se viabilizem, o conhecimento e a compreensão dos processos sociais e culturais presentes na cultura juvenil devem transversalizar a formação docente, a fim de que as necessidades, os anseios e as expectativas dos jovens possam integrar o planejamento e a execu- 
ção das práticas escolares e pedagógicas, sendo potencializadas como recursos de aprendizagem, superando a incompreensão e os conflitos. Carrano (2010) afirma que a crise no Ensino médio perpassa pela crise na percepção sobre a identidade juvenil, já que o aluno é percebido, em muitos casos, como um objeto, em constante preparação para um futuro profissional. Assim, é preciso:

\begin{abstract}
Indagar se o professor e a instituição conhecem, não apenas individualmente, mas social e antropologicamente o sujeito histórico - jovem contemporâneo- que frequenta a escola e que enfrenta desafios inéditos para realizar a sua transição para a vida adulta. [...] As más escolhas pessoais e os desempenhos individuais insatisfatórios diante dos múltiplos espaços-tempos de competição seriam as causas principais das trajetórias de vida truncadas ou mal equacionadas. Em última instância, o insucesso seria resultante da baixa capacidade do indivíduo para produzir competências e biografias suficientemente adequadas ao enfrentamento dos desafios estruturais nos quais ele pouco pode interferir (CARRANO, 2010, p.147).
\end{abstract}

Os problemas da escola também estão presentes na sociedade: o declínio da responsabilidade, o aumento do egoísmo, o sentimento de que os direitos individuais devem vir na frente de tudo, o apetite constante por novidades, o consumismo galopante, as desigualdades crescentes, o medo e a insegurança. Desta forma, Sposito (2010) sugere que é possível compreender o jovem e seus conflitos educacionais, à medida que conhecemos como ele se apropria social e culturalmente dos espaços que ocupa, das interações que mantém, da forma como transita no mundo contemporâneo. A realidade vivenciada por muitos é oposta a normatização e padronização escolar, surgindo conflitos inerentes às formas antagônicas de vida. Desta forma, a escola não deve ser deslocada do seu entorno social e da sua trajetória histórica na humanidade. Todas as mazelas vivenciadas no interior da escola são reflexos de políticas públicas, de interesses hegemônicos, que deslocaram a importância do conhecimento, da pesquisa, do saber para trivialidades necessárias à obtenção de lucros e interesses pessoais.

Existe um consenso de que a escola é necessária e imprescindível para o jovem, trazendo-lhes inúmeros benefícios para o futuro e, por muito tempo, ela foi o local privilegiado de transmissão de saberes e de celebração dos conhecimentos universais. Atualmente, o aluno que chega ao ensino médio encontra um nítido descompasso em relação às suas expectativas, aos seus projetos de vida e a sala de aula. Diante desse desarranjo, ele passa a valorizar o encontro com os amigos, as aulas de Educação Física, a discussão de assuntos comuns nos grupos juvenis, como o "ficar", sexo, drogas, programações para os finais de semana, a interação com o sexo oposto, enfim, uma série de 
objetivos dissonantes daqueles propostos nos planos de ensino dos professores. Corti (2009) discute a diversidade de culturas, desigualdades sociais e econômicas que passaram a integrar o cotidiano escolar e que estão por requerer uma nova escola.

É diante de um público juvenil extremamente diverso, que traz
para dentro da escola as contradições de uma sociedade que
avança na inclusão educacional sem transformar a estrutura so-
cial desigual - mantendo acesso precário à saúde, ao transpor-
te, à cultura, ao lazer e ao trabalho - que o novo Ensino médio
se forja. As desigualdades sociais passam a tensionar a institui-
ção escolar e a produzir novos conflitos (CORTI, 2009, p. 13)

Aliadas às expressões culturais, a sociabilidade é outra dimensão que deve ser considerada quando falamos de juventude. Os amigos ocupam um lugar central na vida juvenil, respondendo às necessidades de comunicação, trocas afetivas e formação de identidade (DAYRELL, 2009). Deve-se considerar que a escola é um dos principais locais de encontro dos jovens e, por isso, eles priorizam as trocas, as conversas e os diálogos com os seus pares, pois nestes momentos podem explicitar diversos dilemas e problemas. De acordo com pesquisa realizada com os jovens brasileiros, os assuntos que eles mais gostariam de falar com os amigos são: drogas (41\%), sexualidade (31\%), violência $(30 \%)$, educação e futuro profissional $(29 \%)$, relacionamentos amorosos (26\%), racismo (23\%), entre outros. (BRASIL, 2013).

A família também constitui importante elemento nesse processo de transição da juventude. Para a grande maioria, a referência familiar é fundamental para a sua constituição enquanto sujeitos. Embora muitas famílias não contem com a presença do pai, a mãe desempenha um papel fundamental na definição de regras, valores e na manutenção do núcleo doméstico (DAYRELL, 2009). É importante destacar que as relações entre as pessoas se modificaram nas últimas décadas, o que se estende à própria família. As preocupações com o crescente volume de trabalho, com o pagamento do cartão de crédito, com a aquisição de um novo carro, enfim, com todas as exigências consumistas da atualidade, impelem pais e mães a exercerem jornadas de trabalho cada vez mais ampliadas, justificando seu esforço para dar aos filhos melhores condições de vida, numa atitude de autosacrifício. Por conta disso, fragilizam-se os vínculos afetivos no ambiente familiar: os presentes, os objetos, o passeio semanal ao shopping passam a exprimir o afeto e o amor dos pais. Com a convivência cada vez mais limitada, os jovens permanecem sozinhos em meio aos seus conflitos, dúvidas e problemas. Em muitos casos, perdeu-se a referência entre distante e próximo, pois os contatos entre pais e filhos são efetuados basicamente on-line (BAUMAN, 2013). 
Essa sublimação do individualismo, atrelada ao imediatismo, promove uma baixa tolerância à autoridade, às normas e às regras da escola. Porém, a própria sociedade tem levado os indivíduos a sentirem-se inseguros ou indecisos em relação às normas que devem seguir e, desta forma, deflagra-se na escola uma grande crise, já que os encaminhamentos e as punições utilizadas no passado, não se mostram eficientes, requerendo que a instituição escolar reorganize suas condutas para garantir o convívio social. Assim, passamos por um momento de transição de paradigmas educacionais e da própria cultura: podemos optar pela manutenção de uma educação, cujo único objetivo é a transmissão de conhecimento, em que a disciplina é entendida como controle e regulação, ou podemos escolher uma educação cidadã, na qual o aluno é protagonista da sua trajetória, concebendo a educação como um processo de construção coletiva do saber, buscando a integralidade do ser humano. Assim, a disciplina é compreendida como um conjunto de regras que estabelece limites, respeitando o desenvolvimento dos estudantes e a sua participação nas definições do que será permitido ou proibido (LA TAYLLE, 2005).

Os desafios para garantir a relação dos jovens com a escola de ensino médio são múltiplos. A democratização deste nível de ensino não é, por si só, garantia de qualidade. Somos desafiados a pensar em uma educação que dê suporte às juventudes, nas suas multiplicidades, qualificando o jovem para o mercado de trabalho, habilitando-o para ingresso no ensino superior, bem como, proporcionando no espaço escolar a vivência da cidadania, para que ele possa constituir-se num sujeito autônomo, capaz de transitar com segurança pelas inúmeras resistências que encontrará na sua transição para a idade adulta. Schlickmann (2013) afirma que a consciência absorve o que desperta o interesse; assim, para despertar o dinamismo e ação, a questão precisa se desprender do óbvio, do cotidiano. Desta maneira, precisa-se pensar em uma escola que ouça os jovens em relação às suas expectativas e projetos, a fim de sintonizar os objetivos individuais e coletivos da juventude com os objetivos escolares e buscar, coletivamente, respostas para esta crise educacional.

\section{Considerações finais}

O presente artigo pretendeu identificar a diversidade de juventudes presentes no meio educacional, analisando como eles se constituem como alunos e a forma de organização das escolas para atender a essa faixa etária. Neste sentido, percebeu-se a complexidade em definir o termo juventude, tendo em vista os múltiplos aspectos que estão presentes na vida juvenil.

Ao percorrer-se historicamente o conceito de juventude, reconhece-se um viés que valoriza os problemas e os desvios. Por longas décadas, os jovens 
foram analisados por olhares adultocêntricos que, a partir das convicções particulares do mundo adulto e de certas definições cronológicas, definiam as características reconhecidas como 'normais', e todos aqueles que se desviassem desses padrões eram considerados como problemas.

Como vimos, muitos estudos priorizam a questão da transitoriedade. Nesses termos, o jovem é visto somente por aquilo que ele virá a ser, não sendo reconhecido como uma pessoa que tem suas prioridades e projetos e que necessita vivê-los na sua contemporaneidade. Devido a essa limitação da visão acerca do jovem, esse aluno de escolas do ensino médio acaba por demandar uma ampliação na ótica dos estudos sobre a juventude. É, de fato, a partir dos anos de 1990 que o jovem passa a ser estudado como protagonista da sua história. Acredita-se que a demanda por estudos se intensificou pelas inúmeras tensões e conflitos que permeiam a escola. Essa nova forma de pesquisar a juventude tem sido fundamental para buscar respostas à crise do ensino médio.

Assim, o presente ensaio teórico atingiu seu objetivo no sentido de demonstrar que os principais atores do ensino médio, os jovens, precisam ser ouvidos e que as suas vozes necessitam integrar as definições e decisões do cotidiano escolar, pois uma escola descolada da realidade, com um currículo distante dos seus projetos, com metodologias tradicionais não irá favorecer a relação com seus alunos e a sua adesão aos projetos escolares. Entende-se que à medida que os atores do contexto educacional estiverem dispostos a estudar a pluralidade das juventudes e a diversidade de fatores que compõem a vida juvenil, estaremos mais próximos de encontrar caminhos que levem à significação da escola.

\section{Referências}

ANDRADE, Eliane Ribeiro. Juventude, exclusão e educação. Movimento-Revista da Faculdade de educação da Universidade Federal Fluminense, Juventude, educação e sociedade, Rio de Janeiro, v. 1. n.1, mai. 2000.

BAUMAN, Zygmunt. Sobre educação e juventude. Rio de Janeiro: Zahar, 2013.

BRASIL (MEC/INEP), Censo Escolar da educação básica 2012. Resumo Técnico. Brasília, DF: Instituto Nacional de Estudos e Pesquisas Educacionais Anísio Teixeira, 2013. Disponível em: <http://download.inep.gov.br/educacao basica/censo escolar/resumos tecnicos/ resumo tecnico censo educacao basica_2012.pdf $>$ Acesso em: 20 jan.2014

.(Secretaria Geral da Presidência da República). Agenda juventude Brasil: pesquisa nacional sobre perfil e opinião dos jovens brasileiros. Brasília, DF: Secretaria Nacional da Juventude, nov. 2013. Disponível em: <http://www.brasil.gov.br/cidadania-e-justica/2014/02/ agenda-juventude-brasil.epub/view> Acesso em: 30 jan.2014 
CARRANO, Paulo Cesar R. O Ensino médio na transição da juventude para a idade adulta. In: FERREIRA, Cristina Araripe et al. (Org.) Juventude e iniciação científica: políticas públicas para o ensino médio. Rio de Janeiro: EPSJV, UFRJ, 2010, p.143-168.

CORTI, Ana Paula. Uma diversidade de sujeitos: juventude e diversidade no Ensino médio. In: Juventude e escolarização: os sentidos do Ensino Médio. Salto para o Futuro. Brasília, DF: Secretaria de Educação a Distância, MEC, Ano XIX, boletim 18, nov. 2009, p.12-15.

DAYRELL, Juarez. Uma diversidade de sujeitos: o aluno do ensino médio - o jovem desconhecido. In: Juventude e escolarização: os sentidos do Ensino Médio. Salto para o Futuro. Brasília, DF: Secretaria de Educação a Distância, MEC, Ano XIX, boletim 18, nov. 2009, p. 16-23.

.O jovem como sujeito social. Revista Brasileira de Educação, Rio de Janeiro, n²4, p. $\overline{40-52}$, set/dez, 2003. Disponível em: $<$ http://www.scielo.br/pdf/rbedu/n24/n24a04.pdf $>$. Acesso em: 02 nov. 2013.

FRIGOTTO, Gaudêncio. Expectativas juvenis e identidade no Ensino médio: Ensino médio no Brasil - "juventudes" com futuro interditado. In: Juventude e escolarização: os sentidos do Ensino Médio. Salto para o Futuro. Brasília, DF: Secretaria de Educação a Distância, MEC, Ano XIX, boletim 18, nov. 2009, p. 24-29.

GARBIN, Elisabete M. Conectados por um fio: alguns apontamentos sobre internet, culturas juvenis e contemporâneas e escola In: Juventude e escolarização: os sentidos do Ensino Médio. Salto para o Futuro. Brasília, DF: Secretaria de Educação a Distância, MEC, Ano XIX, boletim 18 , nov. 2009 , p.30-40.

GROPPO, Luís Antônio. Juventude: ensaios sobre sociologia e história das juventudes modernas. Rio de Janeiro: DIFIL, 2000.

LA TAILLE, Yves de. Indisciplina/disciplina: ética, moral e ação do professor. Porto Alegre: Mediação, 2005

KUENZER, Acácia Z. O ensino médio agora é para a vida: entre o pretendido, o dito e o feito. Educação e Sociedade, Campinas, SP, n.70, abril, 2000.

MELO, Simone Lopes; BORGES, Lívia de O. A transição da universidade ao mercado de trabalho na ótica do jovem. Revista psicologia, ciência e profissão, Brasília, v. 27, n.3, p.376395, 2007. Disponível em: <http://www.scielo.br/pdf/pcp/v27n3/v27n3a02.pdf.> Acesso em: 11 out. 2013.

OLIVEIRA, Adriano M. Entre consumidores e internautas: a outra face da crise do ensino médio no Brasil. 2012. 277 fl. Tese (Doutorado em Educação).Universidade Federal de Santa Maria. Santa Maria, 2012.

SOUSA, Ana Maria B. Educação biocêntrica: tecendo uma compreensão. Pensamento Biocêntrico, [S.1.], v. 5, p. 04-20, 2006.

SPOSITO, Marilia P. Estudos sobre juventude em educação. Revista Brasileira de Educação, Rio de Janeiro, n. ${ }^{\circ} 5$ (especial) Mai/Ago 1997, nº 6. Set/Dez. 1997

.Transversalidades no estudo sobre jovens no Brasil: educação, ação coletiva e cultura. Educação e Pesquisa, São Paulo, v.36, n. especial, p. 095-106, 2010. 
SCHLICKMANN, Vitor. Os sentidos da experiência escolar para os jovens do ensino médio: um estudo em três escolas na cidade de Caxias do Sul/RS. 2013. 197 fl. (Doutorado em Educação).Universidade Federal de Santa Maria. Santa Maria, 2013.

Submissão em: 10/07/2014

Aceite em: 09/08/2014

Mara Regina Zluhan é doutoranda em Educação na Universidade do Vale do Itajaí, professora na Faculdade Avantis e orientadora vocanional da rede estadual de ensino. Desenvolve pesquisas no Grupo Educação e Trabalho na Universidade do Vale do Itajaí nas temáticas: juventude, escola, trabalho, ensino médio e ensino superior, jovens e a escolha, transições acadêmicas e laborais, direitos humanos, etc. Endereço para correspondência: Rua 3122, n 195. Apt. 1001. Centro Balneário Camboriú/SC, Brasil. CEP 88330-290. E-mail: mara@redel.com.br

Tânia Regina Raitz é professora e Pós-doutora em Educação pela Universidade de Barcelona - Espanha, Professora e Pesquisadora no Programa de Pós-Graduação (Mestrado e Doutorado em Educação), Coordenadora do Grupo de Pesquisa Educação e Trabalho da Universidade do Vale do Itajaí Coordenadora de Gestão do PIBID da Univali. E-mail: raitztania@gmail.com 